\title{
Reversible dilative cardiomyopathy after electrical injury: a case report
}

\author{
Eirini Liodaki ${ }^{*}$, Virginia Galati ${ }^{1}$, Martin Bethge ${ }^{2}$, Wolfgang Göpel ${ }^{3}$, Peter Mailaender ${ }^{1}$ and Felix Stang ${ }^{1}$
}

\begin{abstract}
Background: Dilative cardiomyopathy is an uncommon cardiac complication of electric shock.

Case presentation: We report a case of a 12-year-old German boy with a high voltage injury who developed a fourchamber dilative cardiomyopathy, which was diagnosed on the 13th week postburn. One year after the accident, echocardiography showed a normal function of his heart with $64 \%$ ejection fraction and normal cavities' dimensions.

Conclusions: Despite the fact that dilative cardiomyopathy is not very common in electrical injuries but can be fatal, a prolonged echocardiography follow-up for patients with electrical injury could be recommended. Until now this case is the first child with severe burns after electrocution, who developed a reversible dilative cardiomyopathy.
\end{abstract}

Keywords: Reversible dilative cardiomyopathy, Dilative cardiomyopathy, Cardiomyopathy and electrical injury, Cardiomyopathy and burns

\section{Background}

Electrical burns typically comprise only a small percentage (approximately 3-4\%) of total admissions to burn care units $[1,2]$. However, this type of injury is considered one of the most devastating injuries due to its high morbidity and mortality [3] and is also the most frequent cause of amputations in a burn care unit [2]. Electrotrauma is divided between higher and lower voltage injuries with a borderline of 1000 volts [4]. Low voltage injuries typically cause only local disabilities in the place of contact, while high voltage injuries usually induce local disabilities and extensive devastation of deep structures, along with systemic effects [4]. Up to $40 \%$ of serious electrical injuries are fatal. High-voltage electrical injuries are truly devastating and cause long-term morbidity in those who survive including extremity amputations, blindness, and renal failure.

The most common cause of death continues to be cardiac arrest after acute arrhythmias at the scene of the incident secondary to either asystolia or ventricular fibrillation [1]. Electricity has been documented to cause

\footnotetext{
* Correspondence: liodaki.eirini@gmail.com

${ }^{1}$ Department of Plastic, Hand Surgery and Burn Care Unit, University Hospital Schleswig-Holstein, Campus Lübeck, Ratzeburger Alle 160, Lübeck, Germany Full list of author information is available at the end of the article
}

myocardial necrosis, infraction, dysrhythmia, and contractile dysfunction, all of which may be delayed as well as persistent [5].

Dilative cardiomyopathy (DCM) is an uncommon cardiac complication of an electric shock. Only three cases of DCM caused by electrical injury have been reported in the international literature.

We report a case of a young boy with a high voltage injury who developed a reversible four-chamber DCM.

\section{Case presentation}

A 12-year-old German boy suffered from an accidental electrocution with 15,000 volts as he was playing in a railroad car. The boy was intubated at the site of the accident and immediately admitted to our burn care unit with deep partial-thickness and full-thickness burns. He sustained a 70\% total body surface area (TBSA) burn of the face, neck, spine, thorax, abdomen, both arms, and both legs (Fig. 1a-c). A source lesion was noted on his right shoulder, and a ground lesion was visible on his right thigh. Directly after the admission, escharotomy and tracheostomy took place. In the first 24 to 48 hours after the removal of blisters a "wet-wound-dressing" with paraffin gauze dressing and polyhexanide solution was applied. 

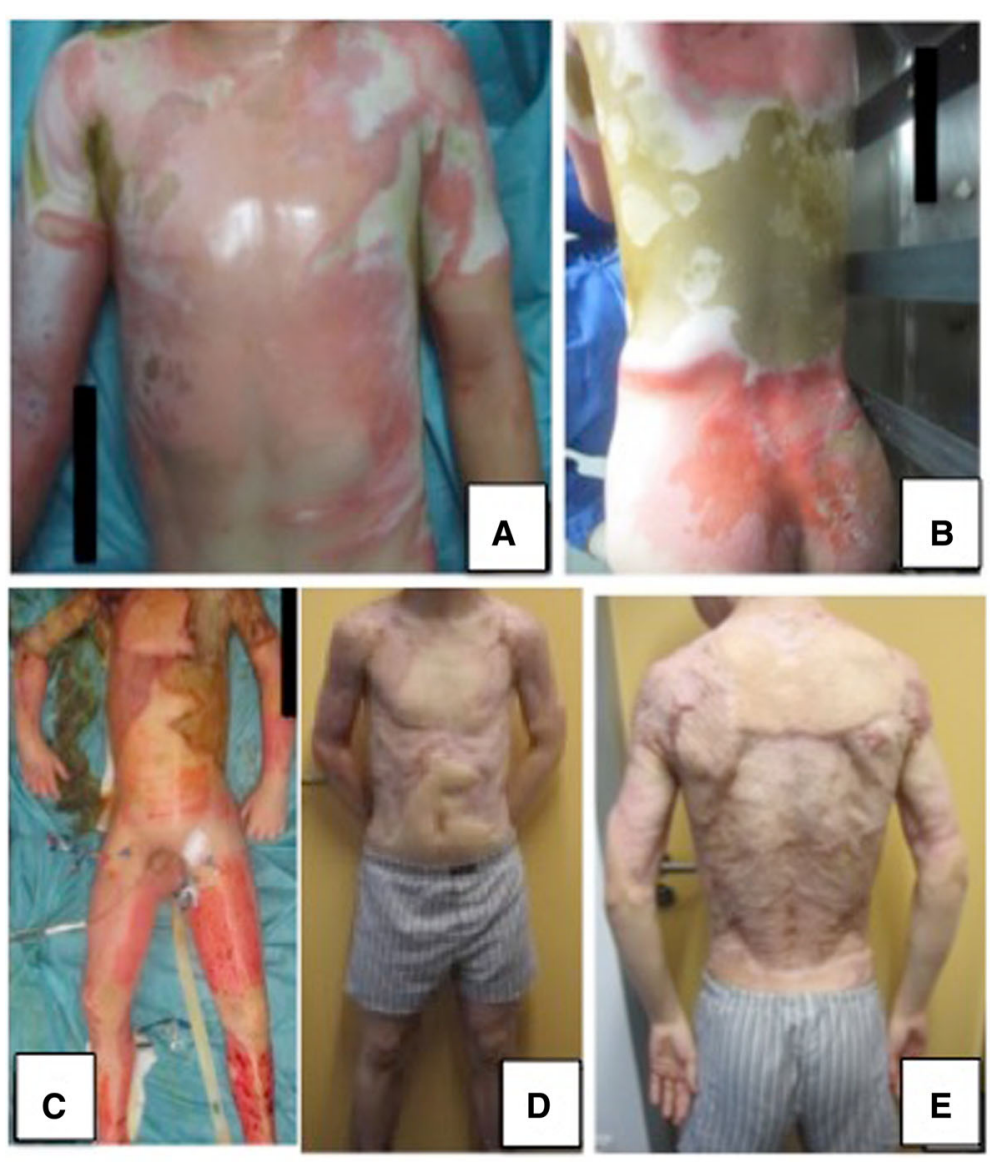

Fig. 1 The 12-year-old boy was intubated at the site of the accident and immediately admitted to our burn care unit with deep partial-thickness and full-thickness burns. He sustained a $70 \%$ total body surface area burn of his face, neck, spine, thorax, abdomen, both arms, and both legs $(\mathbf{a}, \mathbf{b})$. Within the first 3 weeks, seven operations were performed; postoperative status 5 weeks (c) postburn. His appearance 18 months after the accident $(\mathbf{d}, \mathbf{e})$

He was resuscitated according to the Parkland formula. In the first 24 hours, only Ringer lactate solutions and no colloids were used. He was started on a high-calorie diet (enteral feeding). Cardiac monitoring was done for 24 hours and no cardiac dysrhythmias were observed.

Within the first 3 weeks seven operations were performed including dermabrasion, application of Suprathel ${ }^{\circ}$ (PolyMedics Innovations GmbH, Denkendorf, Germany), tangential excision and split-thickness skin graft, epifascial excision, application of Integra ${ }^{\mathrm{Tm}}$ (Integra LifeSciences Corp., Plainsboro, NJ, USA), and autologous keratinocyte transplantation.

The duration of the mechanical ventilation reached 85 days.

In the course of the stationary treatment (135 days) he developed acute renal failure treated with veno-venous hemofiltration for 7 days and acute liver failure treated conservatively.
The boy developed persisting hypotension, edema, and ascites after the 10th week postburn. The hypotension required dobutamine therapy. A chest X-ray showed an increase of the cardiothoracic ratio from 0.50 (at the time of admission) to 0.63 (at this critical point) (Fig. 2). In order to clarify this persisting hypotension, a second echocardiography was performed. The first echocardiography was performed 4 weeks after the accident proving the healthy initial condition of the heart of our young patient. A four-chamber DCM with biventricular dysfunction was diagnosed 13 weeks after the accident: left ventricular ejection fraction (LV-EF) 18\% (Fig. 3).

The most common possible causes of DCM (viruses, infections, drugs, toxins, endocrinologic disorders, metabolic disorders, and arrhythmia) were tested and excluded.

Inotropic therapy was initially required. It began with digitalis and then an application with phosphodiesterase inhibitor (milrinone) followed. A diuretic therapy with 

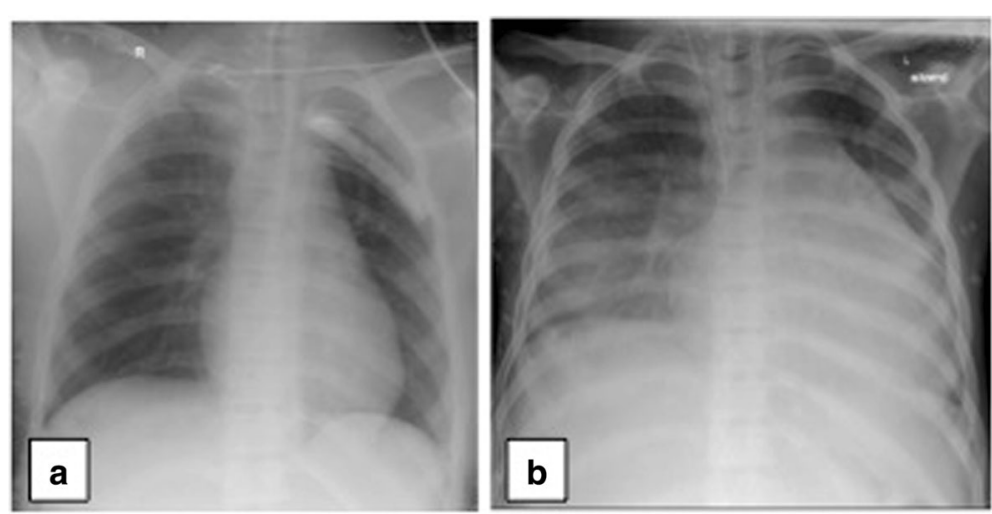

Fig. 2 A chest X-ray showed an increase of the cardiothoracic ratio from $0.50(\mathbf{a})$ at the time of admission to 0.63 (b) at the 10 th week postburn

torasemide was also applied. Then, heart failure therapy followed with angiotensin-converting enzyme (ACE) inhibitor (enalapril), beta blocker, diuretics, and digoxin.

At the point of hospital discharge there was an increase of $\mathrm{EF}(22 \%)$ as well as an increase of the contractility of his heart. The LV end diastolic diameter (LVEDD) reached $58 \mathrm{~mm}$.

One year after the accident, echocardiography showed a normal function of his heart with $64 \% \mathrm{EF}$ and normal cavities' dimensions (LVEDD $51 \mathrm{~mm}$ ). No mitral and tricuspid insufficiency was present.

\section{Discussion}

To the best of our knowledge, there are only three cases of DCM caused by electrical injury reported in the international literature. In these cases the victims were all adults aged 24-57 years without predisposing conditions. Two suffered from a high-voltage electrical injury $(12,600 \mathrm{~V}$ and $13,000 \mathrm{~V})$. One patient died on the third day postburn and an autopsy showed that the cause of death was severe heart failure by acute four-chamber dilated cardiomyopathy. The other two patients died within 18 months after the incident.

The pathophysiological mechanism of DCM secondary to electric shock is not clear. Myocardial dysfunction may be a complication of thermal/electrical injury [1]. This can initially be attributed to fluid shifts that occurred as a result of plasma loss into the burn area, producing a fall in venous return and a decrease in preload [1]. The electric shock could cause myocardial

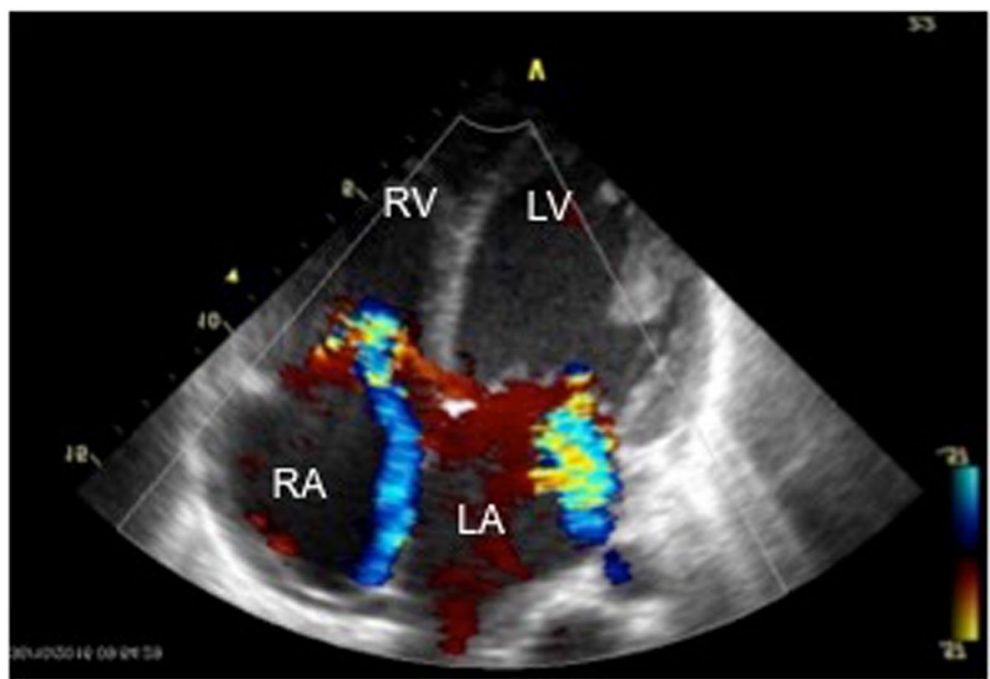

Fig. 3 A four-chamber dilative cardiomyopathy with biventricular dysfunction (left ventricular ejection fraction 18\%) was diagnosed 13 weeks after the accident. The echocardiography findings showed: enlargement of all the heart cavities; a left ventricular end diastolic diameter $65 \mathrm{~mm}$ (normal values $46.8 \pm 6 \mathrm{~mm}$ ); ejection fraction 18\% (normal values 50-65\%); tricuspid annular plane systolic excursion $1 \mathrm{~cm}$ (normal values $>1.6 \mathrm{~cm}$ ); distinct central mitral insufficiency; and moderate tricuspid insufficiency. There was also a high suspicion of secondary pulmonary hypertension in the context of left ventricular insufficiency (systolic pulmonary artery pressure $45 \mathrm{~mm} \mathrm{Hg}+$ central venous pressure). $L A$ left atrium, $L V$ left ventricle, $R A$ right atrium, $R V$ right ventricle 
necrosis, myocardial infraction, arrhythmia, conduction disturbances as well as contractile dysfunction [1]. DCM appearing after an electrical injury could be a result of direct injury to the myocardium (contraction band necrosis) or a result of host's inappropriate response to injury leading to a cytokine-induced myocardial dysfunction [1]. DCM could also be a result of over-resuscitation or cardiotoxic agents [6].

\section{Conclusions}

Until now the above-mentioned case is the first child with severe burns after electrocution (15,000 volts), who developed a reversible DCM. Despite the fact that DCM is not very common in electrical injuries but can be fatal, a prolonged echocardiography follow-up for patients with electrical injury could be recommended.

Availability of data and materials

Our data are freely available to any scientist wishing to use them.

\section{Authors' contributions}

EL selected the data of the patient, wrote the draft, and coordinated the study. VG found the figures and wrote the figure legends. WG provided the information about the treatment of the patient and corrected the draft. MB provided the echocardiography and all data about the echocardiography findings of the patient. PM conceived the study and participated in its design. FS participated in the design of the study and corrected the draft into its final form. All authors read and approved the final manuscript.

\section{Ethics approval and consent to participate}

For that case report (described the course of a disease) no ethics approval from the ethics committee of the University of Lübeck was needed.

\section{Consent for publication}

Written informed consent was obtained from the patient's legal guardian(s) for publication of this case report and any accompanying images. A copy of the written consent is available for review by the Editor-in-Chief of this journal.

\section{Competing interests}

The authors declare that they have no competing interests.

\section{Publisher's Note}

Springer Nature remains neutral with regard to jurisdictional claims in published maps and institutional affiliations.

\section{Author details}

'Department of Plastic, Hand Surgery and Burn Care Unit, University Hospital Schleswig-Holstein, Campus Lübeck, Ratzeburger Alle 160, Lübeck, Germany. ${ }^{2}$ Pediatric Cardiology, Paracelcus Health Center, Lübeck, Germany. ${ }^{3}$ Pediatric Department, University Hospital Schleswig-Holstein, Campus Lübeck, Lübeck, Germany.

Received: 2 February 2018 Accepted: 1 October 2018

Published online: 08 November 2018

\section{References}

1. Jaber JJ, Vibhakar DB. High voltage induced myocardial dysfunction with associated acute four-chamber dilated cardiomyopathy: a case report and review of the literature. Burns. 2012:38(7):e28-34.

2. Azzena B, Tocco-Tussardi I, Pontini A, Presman B, Huss F. Late complications of high-voltage electrical injury might involve multiple systems and be related to current path. Ann Burns Fire Disasters. 2016;29(3):192-4.

3. Ghavami Y, Mobayen MR, Vaghardoost R. Electrical burn injury: a five-year survey of 682 patients. Trauma Mon. 2014;19(4):e18748.
4. Lipovy B, Kaloudova $Y$, Rihova $H$, et al. High voltage electrical injury: an 11-year single center epidemiological study. Ann Burns Fire Disasters. 2014;27(2):82-6.

5. Buono LM, DePace NL, Elbaum DM. Dilated cardiomyopathy after electrical injury: report of two cases. J Am Osteopath Assoc. 2003;103(5):247-9.

6. Kraft R, Herndon DN, Finnerty CC, Shahrokhi S, Jeschke MG. Occurrence of multiorgan dysfunction in pediatric burn patients: incidence and clinical outcome. Ann Surg. 2014;259(2):381-7.

\section{Ready to submit your research? Choose BMC and benefit from:}

- fast, convenient online submission

- thorough peer review by experienced researchers in your field

- rapid publication on acceptance

- support for research data, including large and complex data types

- gold Open Access which fosters wider collaboration and increased citations

- maximum visibility for your research: over 100M website views per year

At BMC, research is always in progress.

Learn more biomedcentral.com/submissions 